\title{
A Natural Tetrahydropyrimidine, Ectoine, Ameliorates Ischemia Reperfusion Injury after Intestinal Transplantation in Rats
}

\author{
Thomas Pech $^{\text {a }}$ Ichiro Ohsawa ${ }^{\text {a, c }}$ Michael Praktiknjo ${ }^{a}$ Marcus Overhaus ${ }^{a}$ \\ Sven Wehner ${ }^{\mathrm{a}}$ Martin von Websky ${ }^{\mathrm{a}}$ Kareem Abu-Elmagd ${ }^{\mathrm{d}}$ \\ Gerhild van Echten-Deckert ${ }^{b}$ Joerg C. Kalffa Nico Schaefer ${ }^{\mathrm{a}}$ \\ ${ }^{a}$ Department of Surgery, and ${ }^{b}$ Kekulé-Institute, LIMES Membrane Biology and Lipid Biochemistry Unit, University \\ of Bonn, Bonn, Germany; ' Department of Hepatobiliary Pancreatic Surgery, Mie University Graduate School of \\ Medicine, Tsu, Japan; ${ }^{d}$ Division of Intestinal Transplantation, Thomas E. Starzl Transplantation Institute, University \\ of Pittsburgh, Pittsburgh, Pa., USA
}

\section{Key Words}

Small bowel transplantation - Ischemia reperfusion injury • Tetrahydropyrimidine $\cdot$ Ectoine

\begin{abstract}
Background/Aims: Ischemia reperfusion (I/R) injury after small bowel transplantation leads to inflammatory reactions and loss of structural integrity with subsequent graft contractile dysfunction in the early postoperative phase. The natural tetrahydropyrimidine ectoine (1-,4-,5-,6-tetrahydro2-methyl-4-pyrimidine carboxylic acid; THP) protects the ileal mucosa and muscularis against effects of I/R injury in an experimental model of isolated graft reperfusion. The effects of THP treatment were evaluated in an established experimental intestinal transplant model. Methods: Isogenic, orthotopic small bowel transplantation was performed in Lewis rats ( $6 \mathrm{~h}$ cold ischemia time). Perioperative THP treatment (intraluminal/intravascular) groups were compared to vehicle-treated animals (after 3 and $24 \mathrm{~h}$ ) and non-transplanted controls ( $n=5 /$ group). Park's score defined the effects of I/R injury. The infiltration of neutrophils, monocytes and macrophages, mRNA expression of IL- 6 and TNF- $\alpha$, serum levels of IL- 6 and NO and smooth muscle contractility
\end{abstract}

were evaluated. Results: Improved graft outcome after intraluminal and intravascular THP treatment was defined by considerably ameliorated neutrophil infiltration and less histological signs of $\mathrm{I} / \mathrm{R}$ injury $(\mathrm{p} \leq 0.05)$. In the presence of THP, mRNA expression of IL- 6 and TNF- $\alpha$ and IL- 6 and NO serum levels were reduced and smooth muscle function was improved. Conclusion:THP treatment offers protection against the effects of $\mathrm{I} / \mathrm{R}$ injury in intestinal transplantation in vivo, however, only as supplementary treatment option.

Copyright $\odot 2012$ S. Karger AG, Basel

\section{Introduction}

Ischemia reperfusion (I/R) injury remains one of the burdens in intestinal transplantation, associated with graft motoric dysfunction and inflammatory reactions in the graft as well as loss of structural integrity in the early postoperative phase. The damaged intestinal layers can result in bacterial translocation with subsequent sepsis triggering multi-organ failure with reduced graft and patient survival. Several reports identified I/R injury, besides graft injury through other traumatic factors like brain death of the donor and surgical manipulation, as

\section{KARGER \\ Fax +4161306 1234 \\ E-Mail karger@karger.ch}

www.karger.com
(C) 2012 S. Karger AG, Basel

$1015-2008 / 13 / 0802-0102 \$ 38.00 / 0$

Accessible online at:

www.karger.com/pat
Nico Schaefer, MD

Department of General Surgery, Universitätsklinikum Bonn

Sigmund-Freud-Strasse 25

DE-53105 Bonn (Germany)

E-Mail nico.schaefer@ukb.uni-bonn.de 
key player leading to graft damage by the generation of reactive oxygen species, expression of heat shock proteins and potential activation of innate immune events [1]. The natural tetrahydropyrimidine ectoine (1-,4-,5-,6-tetrahydro-2-methyl-4-pyrimidine carboxylic acid; THP) has been shown to protect the ileal mucosa and muscularis against effects of I/R injury in an experimental model of isolated graft reperfusion [2].

THP is a so-called compatible solute, a class of compounds that are biologically inert and do not interfere with cellular functions even when they accumulate at high concentrations in the cytoplasm [3]. It is produced by extremophilic microorganisms under exceedingly dry and salty conditions or high UV radiation stress in order to control osmotic stress. Halophilic bacteria, e.g. Ectothiorhodospira halochloris or Halomonas elongate, only survive through THP production $[3,4]$. THP is an amorphous water-binding molecule forming large hydrate envelopes, stabilizing the natural structure of biopolymers, e.g. proteins, and nucleic acids by minimizing their denaturation [5-7]. The membrane-stabilizing effects and improved hydration by ectoine led to its extended use as topic application protecting skin cells from UVA irradiation [8]. Ectoine protects epidermal Langerhans' cells effectively and supports natural repair mechanisms of these cells, and it reduces the number of apoptotic keratinocytes due to high UV stress [9]. Sydlik et al. recently reported about dose-dependently reduced nanoparticleinduced neutrophil inflammation in the lung under in vitro and in vivo conditions, suggesting a mechanism involving the stabilization of macromolecules at the outer cell surface [10]. During small bowel transplantation (SBTx), the grafts are exposed to a variety of environmental stress including intraluminal and intravascular events. The protective potential of THP reported by Wei et al. [2] is based on isolated reperfusion in a standard organ bath focused on I/R injury. In this study, we evaluated the tissue-protective effect of THP in vivo in an orthotopic SBTx model in rats.

\section{Materials and Methods}

\section{Animals}

Inbred male Lewis rats weighing 180-200 g were obtained from Charles River WIGA GmbH (Sulzfeld, Germany). All experiments were performed in accordance with the federal law regarding the protection of animals. The principles of laboratory animal care (NIH publication No. 85-23, revised 1985) were followed. The animals were maintained on a 12-hour light/dark cycle and provided with commercially available chow (Altromin, Lage, Germany) and tap water ad libitum.

THP Ameliorates I/R Injury after

Intestinal Transplantation
Dose Finding and Administration Route

In preliminary experiments, different administration routes were evaluated with a THP dose of $5 \mathrm{mg} / \mathrm{kg}$ body weight. In one group, THP was given 30 min before organ preservation intravenously (i.v.), while the small bowel was flushed intraluminally (i.l.) with saline solution. A second group received the same regimen of donor treatment but additionally THP i.v. directly before reperfusion after the transplantation (recipient treatment). The histological alterations and intestinal injury were assessed by a grading system as established by Park et al. [11,12] and the evaluation of myeloperoxidase (MPO)-positive infiltration of neutrophils (see Histological, Histochemical and Immunohistochemical Evaluation below). With no additional effects by the recipient treatment, the administration strategy for this study was defined as THP donor treatment with i.v. administration at $30 \mathrm{~min}$ before preservation and i.l. flushing during organ harvest.

According to previous results by Wei et al. [2], with experiments at a dose of $5 \mathrm{mg} / \mathrm{kg}$ body weight THP $(0.48 \mathrm{mM})$, and other reports $[5,13,14]$ from in vitro experiments with concentrations from 100 to $800 \mathrm{mM}$, dose finding experiments for this in vivo study were indispensable. Therefore, we evaluated a range from 5 to $500 \mathrm{mg} / \mathrm{kg}$ body weight $(4.8-48 \mathrm{mM})$ in preliminary in vivo experiments in this study using donor treatment as described. Since no beneficial effects in Park's score or neutrophil infiltration were achieved at $500 \mathrm{mg} / \mathrm{kg}$ compared to $50 \mathrm{mg} / \mathrm{kg}$, the latter dosage was chosen for further evaluation. Toxicity effects evaluated by hemogram, lactate dehydrogenase, aspartate transaminase, alanine transaminase and creatinine kinase have not been observed up to $500 \mathrm{mg} / \mathrm{kg}$ (results not shown).

Accordingly, the experiments in this study were performed with $50 \mathrm{mg} / \mathrm{kg}$ THP (i.l. flush and i.v. donor treatment), whereas saline was used in controls (i.l. and i.v. donor treatment).

\section{Experimental Groups}

The in vivo effects of THP on intestinal I/R injury were evaluated by orthotopic SBTx in 4 groups (Lewis-Lewis; $\mathrm{n}=5$ transplantations per group - THP $50 \mathrm{mg} 3 \mathrm{~h}$, THP $50 \mathrm{mg} 24 \mathrm{~h}$, vehicle $3 \mathrm{~h}$ and vehicle $24 \mathrm{~h}$ ), while non-transplanted animals (Lewis; $\mathrm{n}=5$ ), which underwent no operative procedures, served as additional controls (control). After organ retrieval, grafts were stored for a total ischemia time of $6 \mathrm{~h}$ in University of Wisconsin (UW) solution at $4{ }^{\circ} \mathrm{C}$. In the 2 treatment groups, THP $(50 \mathrm{mg} / \mathrm{kg}$ body weight) was administered i.v. during the retrieval operation after flushing with UW solution followed by i.l. flushing with saline also containing $50 \mathrm{mg} / \mathrm{kg}$ body weight THP. The vehicle controls received UW solution and saline only as carrier solution. At 3 or $24 \mathrm{~h}$ after reperfusion, all animals in the 2 treatment and 2 vehicle control groups were sacrificed by an isoflurane inhalation anesthesia overdose for further analysis.

\section{Small Bowel Transplantation}

Syngeneic orthotopic SBTx was performed in Lewis rats as previously described under isoflurane inhalation anesthesia [15]. The mean operation time did not differ significantly between all transplant groups. The mean donor operation time was $52 \mathrm{~min}$ in both groups sacrificed after $3 \mathrm{~h}$ (vehicle: $48-56 \mathrm{~min}$; THP-treated animals: $50-55 \mathrm{~min}$ ) and $49 \mathrm{~min}$ in both groups sacrificed after 24 h (vehicle: $43-56 \mathrm{~min}$; THP-treated animals: $45-55 \mathrm{~min}$ ). The mean recipient operation time was $120 \mathrm{~min}$ in the vehicle group sacrificed after $3 \mathrm{~h}, 125 \mathrm{~min}$ in the THP group sacrificed after 
$3 \mathrm{~h}, 127 \mathrm{~min}$ in the vehicle group sacrificed after $24 \mathrm{~h}$ and $121 \mathrm{~min}$ in the THP group sacrificed after $24 \mathrm{~h}$.

\section{Histological, Histochemical and Immunohistochemical}

Evaluation

All probes were analyzed in a blinded way by two authors without knowledge of the experimental groups. According to the preliminary experiments in this study, the histological alterations and intestinal injury in all transplanted groups were assessed by a grading system as established by Park et al. [11, 12]. Whole mounts of the distal jejunum were prepared and fixed with ethanol or paraformaldehyde. MPO-positive neutrophils were detected by staining with Hanker-Yates reagent (Polysciences Europe $\mathrm{GmbH}$, Eppelheim, Germany) and quantified by counting 5 randomly chosen areas in each specimen.

Infiltrating monocytes and macrophages were quantified in the same manner after staining with primary anti-CD68 antibodies (mouse-anti-rat; ED1; 1:200 kept at $4^{\circ} \mathrm{C}$ overnight; Serotec $\mathrm{GmbH}$, Düsseldorf, Germany) and secondary donkey-antimouse-Cy3 antibodies (1:200; Dianova GmbH, Hamburg, Germany). In all staining procedures, secondary antibodies without ED1 preincubation were used in parallel to ensure specificity.

Real-Time Reverse Transcription Polymerase Chain Reaction

Mediator messenger RNA (mRNA) expression in the intestinal muscularis was analyzed in vehicle- and THP-treated animals at 3 and $24 \mathrm{~h}$ after reperfusion. Total RNA extraction was performed using the RNeasy Mini Kit (Qiagen, Hilden, Germany) according to the provider's protocol. Aliquoted RNA (200 ng) was processed for complementary DNA (cDNA) synthesis. Expression of mRNA was quantified by a reverse transcription-polymerase chain reaction (RT-PCR) with gene expression assays for 18s [607024], tumor necrosis factor (TNF)- $\alpha$ [Rn99999017_m1] and interleukin (IL)-6 [Rn00561420_m1] (Taqman Gene Expression Assay; Applied Biosystems, Darmstadt, Germany) as for inflammatory responses as described previously [16]. Each mediator-specific amplification was normalized to an endogenous control (18s). The PCR reaction was performed in Universal PCR Mastermix on an AbiPrism 7900 HT Fast Real-Time PCR System (Applied Biosystems) as recommended by the manufacturer. Relative quantification was performed using the comparative $\mathrm{C} \tau$ method as described previously by Schmittgen et al. [17].

Determination of Nitric Oxide Metabolites and Cytokines

Nitrite and nitrate at 3 and $24 \mathrm{~h}$ after reperfusion were quantified in the rat serum using Nitrate/Nitrite Colorimetric Assay Kit (Cayman Chemical, Ann Arbor, Mich., USA) following the instructions by the manufacturer. Serum levels of IL- 6 were measured by an IL-6 ELISA Kit (R\&D Systems, Wiesbaden, Germany).

\section{Functional Studies}

Mechanical in vitro activity of the mid-jejunum was evaluated at $24 \mathrm{~h}$ after reperfusion using mucosa-free smooth muscle strips of the circular muscularis as described previously [18]. After recording spontaneous contractility for $30 \mathrm{~min}$, dose-response curves were generated using increasing doses of the muscarinic agonist bethanechol (1-300 $\mu \mathrm{M})$ for $10 \mathrm{~min}$ and intervening wash periods (Krebs Ringer buffer (KRB) solution) of $10 \mathrm{~min}$. The contractile response was recorded and analyzed with ADI Chart ${ }^{\odot}$ software (ADI, Heidelberg, Germany) and calculated as grams per square millimeter per second by conversion of the weight and length of the strip to square millimeters of tissue.

Drugs and Solutions

A standard KRB solution was used as described previously [18]. KRB constituents and bethanechol were purchased from Sigma-Aldrich Chemie GmbH (Taufkirchen, Germany) and from Merck KGaA (Darmstadt, Germany). Phosphate-buffered saline was purchased from Lonza (Verviers, Belgium) and THP from Merck (Darmstadt, Germany).

\section{Data Analysis}

Results are expressed as means \pm SD ( $n=5-8$ /group). Statistical analysis consisted of $t$ test or one-way ANOVA followed by Bonferroni or Dunnett's multiple comparison test. $\mathrm{p} \leq 0.05$ was considered significant. SPSS Statistics 17.0 (SPSS GmbH Software, Munich, Germany) was used for statistical analysis.

\section{Results}

\section{THP Improves Intestinal Tissue Quality}

The histological evaluation based on Park's score (fig. 1) revealed severe signs of I/R injury in both treatment groups at $3 \mathrm{~h}$ after reperfusion with grading scores ranging from 4 to 7 with no significant differences $(\mathrm{p}=$ 0.804 ) between vehicle (mean grading score: $5.5 \pm 1.4$ ) and THP (mean grading score: $5.3 \pm 0.7$ ) treatment. However, at $24 \mathrm{~h}$ after reperfusion, the grading scores varied from 3 to 4 (mean grading score: $3.2 \pm 0.4$ ) in vehicle- and from 2 to 3 (mean grading score: $2.4 \pm 0.5$ ) in THP-treated animals with significantly improved preservation of intestinal grafts by THP treatment ( $\mathrm{p}=$ 0.026).

\section{THP Reduces Neutrophil Infiltration into the Intestinal Muscle Layer}

As shown in figure 2, vehicle treatment led to a significant infiltration of MPO-positive cells into the intestinal muscle layer after $3 \mathrm{~h}(10.27 \pm 3.89$ cells/field; $\mathrm{p}=$ $0.006)$ and $24 \mathrm{~h}(67.88 \pm 18.16$ cells/field; $\mathrm{p}=0.003)$ following transplantation when compared to non-transplanted controls $(1.28 \pm 0.11$ cells/field). It becomes clear from these figures that THP treatment considerably prevented infiltration of MPO-positive cells into the intestinal muscularis after transplantation. Thus, at $3 \mathrm{~h}(3.96$ \pm 1.85 cells/field; $\mathrm{p}=0.025)$ and $24 \mathrm{~h}(29.84 \pm 9.82$ cells/ field; $\mathrm{p}=0.016$ ), the amount of MPO-positive cells in the intestinal muscularis of rats treated with THP was significantly reduced compared to vehicle-treated control animals (fig. 2). Nevertheless, the number of MPO-positive cells infiltrated in the intestinal muscle layer in 
Fig. 1. THP improves intestinal tissue quality evaluated with Park's score grading system. Representative histological sections of rat small bowel grafts of THPand vehicle-treated animals at 3 and $24 \mathrm{~h}$ after transplantation: $\mathbf{A}$ isogenic transplanted animal with vehicle treatment and transmucosal infarction at $3 \mathrm{~h}$, B isogenic transplanted animal with THP treatment presenting denuded villi at $3 \mathrm{~h}$, C vehicletreated animal at $24 \mathrm{~h}$ with epithelial lifting along villous sides and D THP-treated animal at $24 \mathrm{~h}$ with more extended subepithelial space. Data are expressed as means $\pm S D\left({ }^{*} \mathrm{p} \leq 0.05\right.$ vs. vehicle at the same time point).
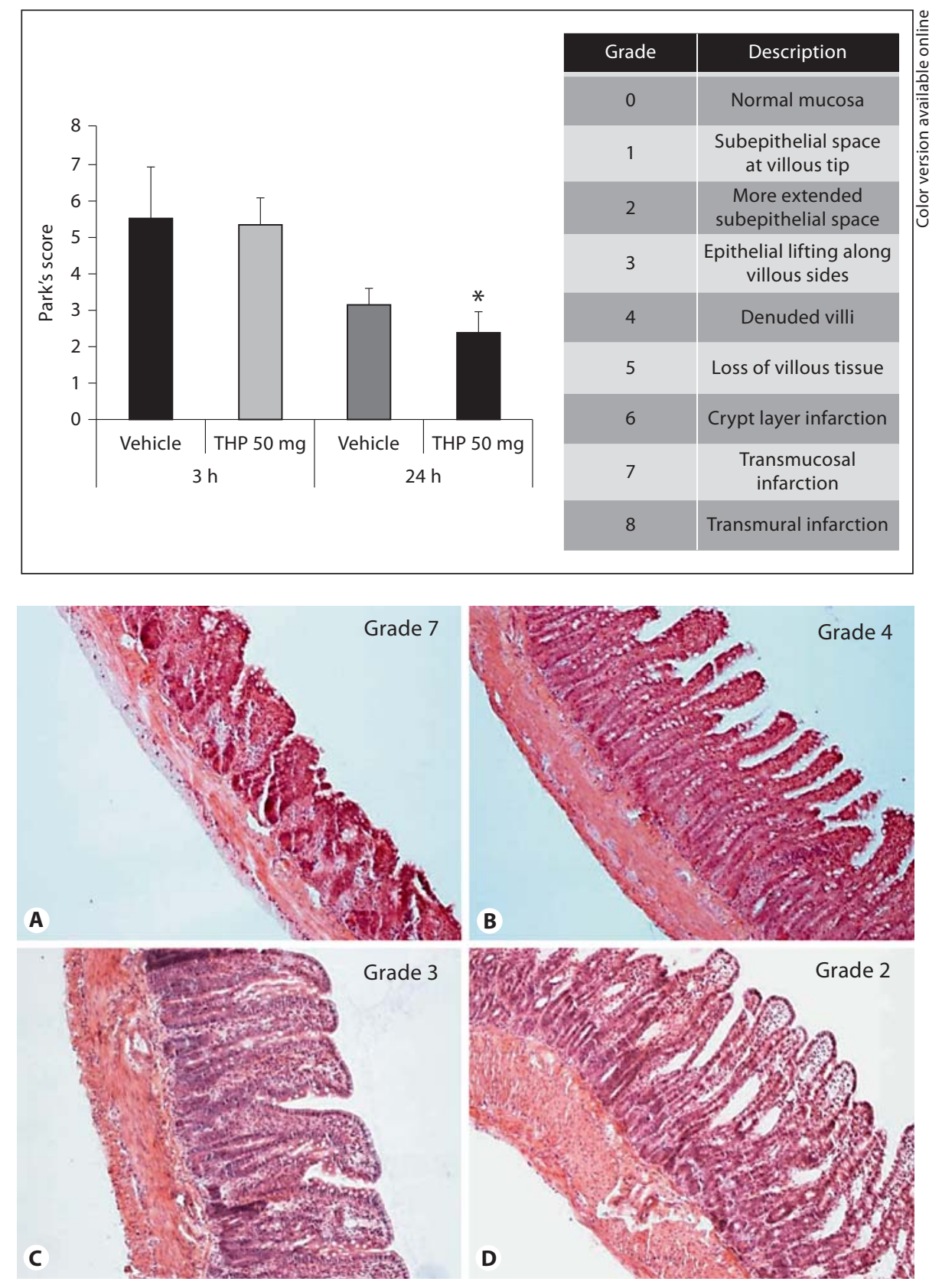

THP-treated animals was significantly increased when compared to non-transplanted controls (at $24 \mathrm{~h} ; \mathrm{p}=$ 0.007).

\section{THP Does Not Affect Infiltration of Monocytes and Macrophages into the Intestinal Muscle Layer}

All transplanted animals exhibited a significantly increased infiltration of ED1-positive cells into the intestinal muscularis at $24 \mathrm{~h}$ after reperfusion compared to nontransplanted controls $(29.04 \pm 9.16$ cells/field; $\mathrm{p} \leq 0.05$; fig. 3). Thus vehicle-treated animals exhibited $57.00 \pm$ 7.22 cells/field, whereas in THP-treated animals this number was even slightly more increased amounting to $64.40 \pm 8.99$ cells/field ( $\mathrm{p}=0.884$ vs. vehicle treatment).

\section{THP Slightly Reduces Inflammatory Cytokine mRNA Expression}

As depicted in figure 3, transcription of the proinflammatory cytokine IL- 6 was substantially induced albeit with high standard deviations at $3 \mathrm{~h}$ after isogenic 
Fig. 2. THP attenuates neutrophil infiltration into the intestinal muscle layer. MPO staining of muscularis whole mounts reveals the infiltration of polymorphonuclear neutrophils into the intestinal muscularis following transplantation. A Nontransplanted control with marginal infiltration; B, D vehicle treatment at $3 \mathrm{~h}$ (slight infiltration) and $24 \mathrm{~h}$ (heavy infiltration), respectively; C, E THP treatment at $3 \mathrm{~h}$ (marginal infiltration) and $24 \mathrm{~h}$ (slight infiltration), respectively. Data are expressed as means $\pm \mathrm{SD}\left({ }^{*} \mathrm{p} \leq 0.05\right)$.
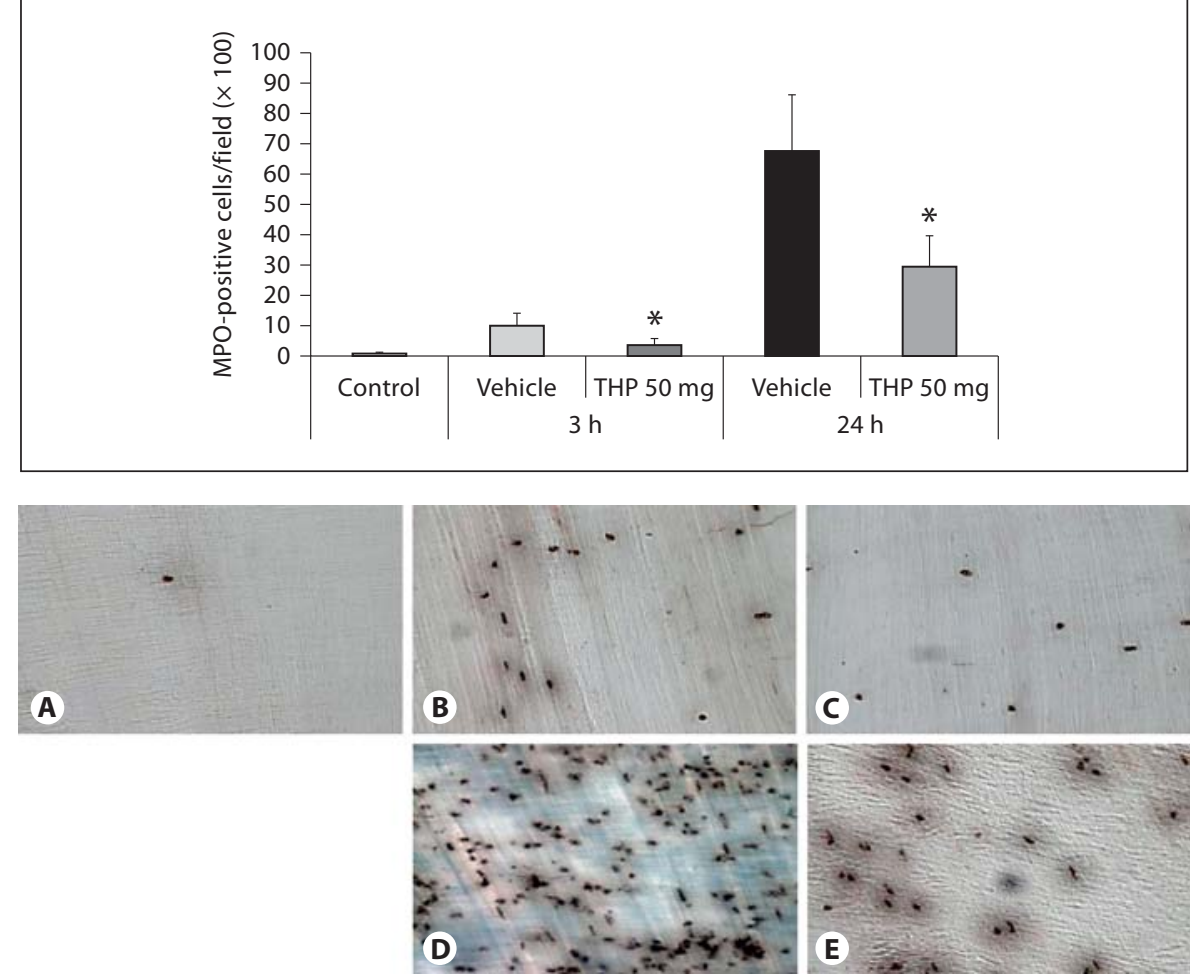

SBTx in the vehicle-treated group (1,709-fold) relative to non-transplanted controls. THP treatment (1,252-fold) considerably reduced transcription of IL- 6 when compared to vehicle treatment $(\mathrm{p}=0.707)$ However, due to the high variability among individual animals, no significance could be obtained. At $24 \mathrm{~h}$ after reperfusion, the IL-6 mRNA levels were largely reduced in both treatment groups amounting to an approximately 50 -fold increase relative to non-transplanted animals.

The relative transcription level of TNF- $\alpha$ increased significantly in both transplanted groups (THP: 6-fold; vehicle: 8 -fold; $p=0.650$ ) relative to non-transplanted controls (fig. 3). This increase persisted over time. Thus at $24 \mathrm{~h}$ after reperfusion, the same pattern of relative TNF- $\alpha$ transcript amounts was observed in both THP(7-fold) and vehicle-treated (8-fold) animals.

\section{THP Reduces Systemic Reactions}

As illustrated in figure 3, changes of the IL-6 serum levels correspond to changes of IL- 6 mRNA expression in intestinal muscularis. At $3 \mathrm{~h}$ after transplantation in rats treated with THP, IL-6 serum concentration was lower $(1,960.58 \pm 1,177.65 \mathrm{pg} / \mathrm{ml})$ than in the vehicle-treated group $(2,313.20 \pm 1,571.20 \mathrm{pg} / \mathrm{ml} ; \mathrm{p}=1.000)$, whereas at
$24 \mathrm{~h}$ after reperfusion, no differences appeared between THP- $(169.76 \pm 23.11 \mathrm{pg} / \mathrm{ml})$ and vehicle-treated (155.06 $\pm 51.61 \mathrm{pg} / \mathrm{ml})$ animals.

Serum nitric oxide (NO) levels were also reduced by THP treatment at $3 \mathrm{~h}$ following transplantation (3.08 \pm $1.43 \mu \mathrm{M})$ compared to vehicle-treated recipients (5.38 \pm $2.99 \mu \mathrm{M}$; fig. 3). Note that the same pattern was observed in the later phase at $24 \mathrm{~h}$, when THP treatment led to lower NO serum levels $(5.68 \pm 1.80 \mu \mathrm{M})$ compared with the respective vehicle treatment $(9.183 \pm 4.75 \mu \mathrm{M}$; fig. 3$)$.

\section{Functional Studies}

As illustrated in figure 4, smooth muscle contractility of both transplanted groups was massively reduced ( $\mathrm{p} \leq$ $0.05)$ compared to non-transplanted controls following stimulation with $100 \mu \mathrm{M}$ bethanechol $(7.55 \pm 0.80$ $\left.\mathrm{g} / \mathrm{mm}^{2} / \mathrm{s}\right)$. THP treatment $\left(0.67 \pm 0.27 \mathrm{~g} / \mathrm{mm}^{2} / \mathrm{s}\right)$ resulted in a $91 \%$ decreased contractility compared to non-transplanted controls, while vehicle treatment $(0.44 \pm 0.19$ $\mathrm{g} / \mathrm{mm}^{2} / \mathrm{s}$ ) led to a $94 \%$ reduction compared to non-transplanted controls. Besides the massive dysfunction in both treatment groups, THP treatment led to improved $(0.23$ $\left.\mathrm{g} / \mathrm{mm}^{2} / \mathrm{s} ; \mathrm{p}=1.000\right)$ smooth muscle contractility compared to vehicle treatment. 

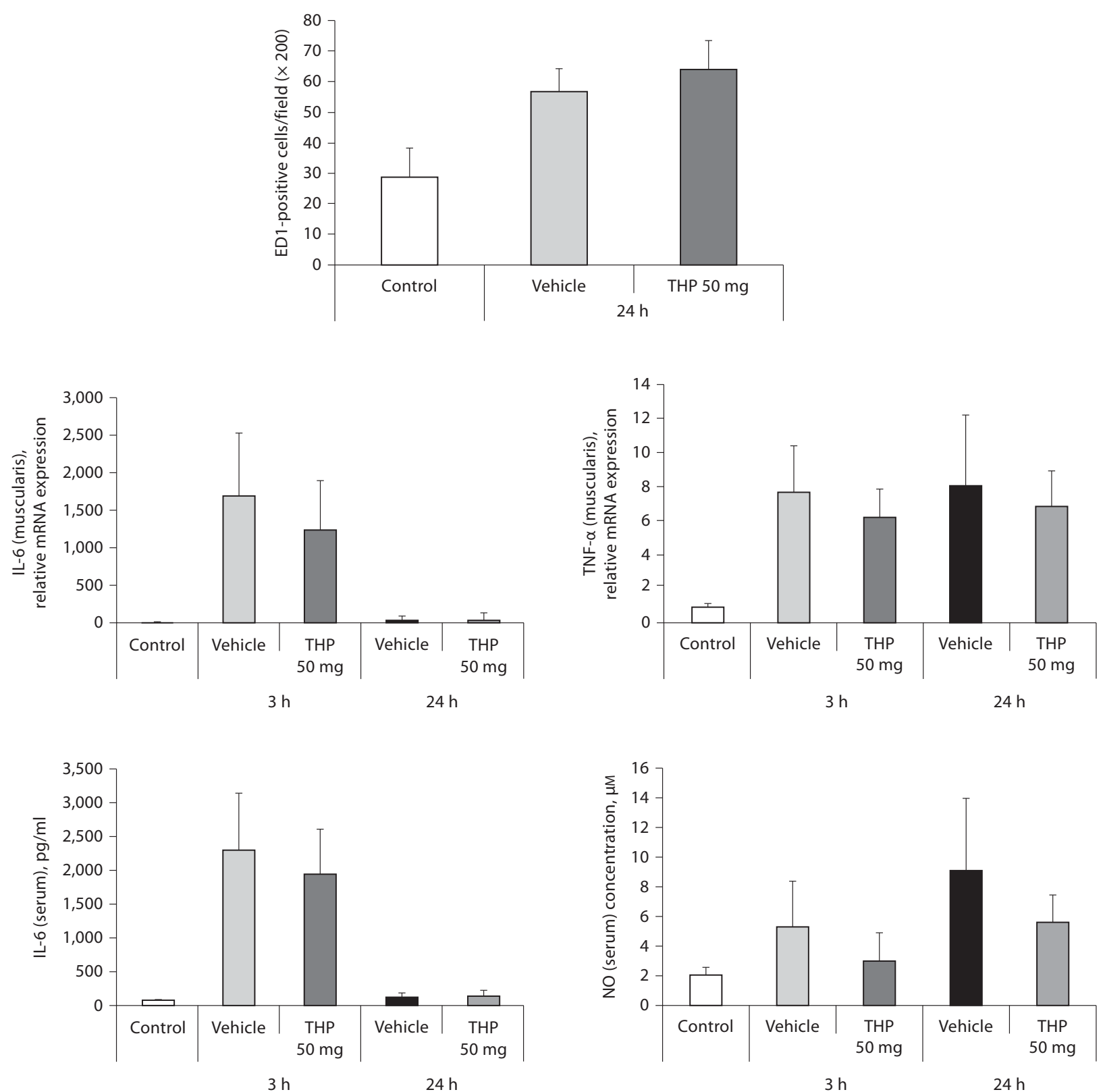

Fig. 3. THP slightly reduces the transcription of inflammatory cytokines without affecting the infiltration of ED1-positive monocytes and macrophages in the intestinal smooth muscle layer after transplantation. The number of ED1-positive cells was determined at $24 \mathrm{~h}$ after transplantation in animals pretreated with either vehicle or THP as well as in non-transplanted controls.

Transcript amounts of IL- 6 and TNF- $\alpha$ were determined by realtime PCR in the muscle layer of controls as well as in vehicle- or THP-treated animals at 3 and $24 \mathrm{~h}$ after transplantation as indicated. IL- 6 and NO serum levels were evaluated as described in Materials and Methods. All data are expressed as means \pm SD. 


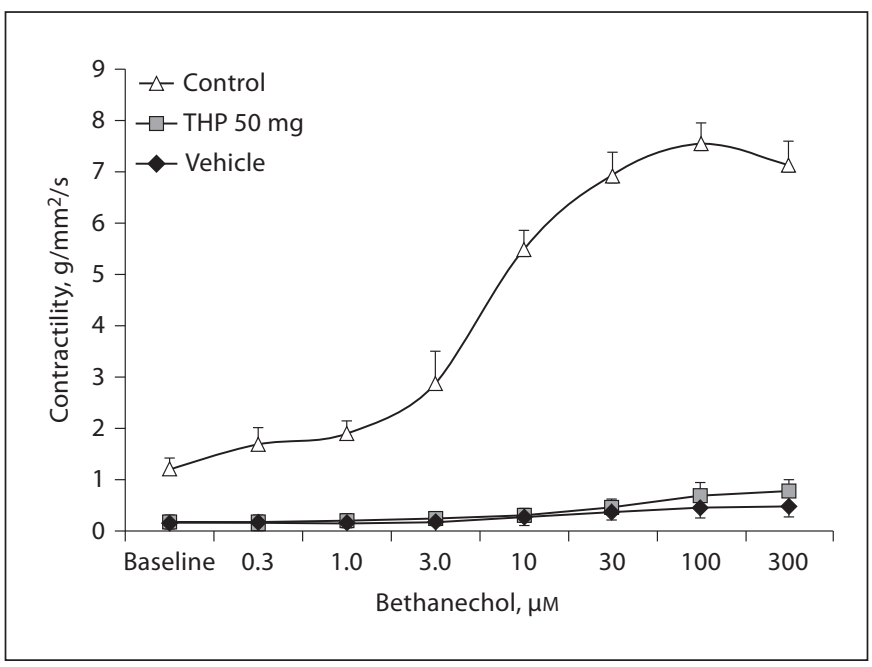

Fig. 4. Bethanechol dose-response curves of smooth muscle contractile activity at $24 \mathrm{~h}$ after reperfusion of animals with THP or vehicle treatment and non-transplanted controls. The contractile response to bethanechol is extensively reduced in transplanted rats after vehicle or THP treatment. Upon stimulation with 100 $\mu \mathrm{M}$ bethanechol, THP improves smooth muscle function compared to vehicle treatment by approximately $52 \%$. Data are expressed as means \pm SD.

\section{Discussion}

In the present study we used an established orthotopic isogenic transplant model $[15,19,20]$, and confirmed the tissue-protective effect of THP in this in vivo model as previously reported in a small bowel model of cold ischemia and subsequent warm in vitro reperfusion [2]. The preliminary experiments pointed to a dosage of 50 $\mathrm{mg} / \mathrm{kg}$ body weight for donor pretreatment and required i.l. use. However, no superior results were obtained by treatment of the recipients with a similar dosage. The occurrence of I/R injury, as evaluated by histological grading, was not affected by intravascular and i.l. treatment with THP at $3 \mathrm{~h}$ after transplantation. Interestingly, only at a later time point $(24 \mathrm{~h})$ after transplantation, THP treatment clearly diminished I/R injury as predicted by the in vitro study of Wei et al. [2]. This tissue-protective effect of THP pertains mainly the intestinal mucosa known to be much more vulnerable to I/R injury than the intestinal muscularis [21]. Nevertheless, THP considerably prevented neutrophil infiltration into the intestinal muscle layer, which mainly occurs during the first days after transplantation. This effect was accompanied by an improved smooth muscle function at least when compared with vehicle-treated animals. However, the con- tractility was still scarce in all transplanted animals, independent from THP or vehicle treatment, indicating that additional mechanisms are essential to protect the smooth muscle function.

Similar to the present study, a reduction of neutrophil infiltration by THP, independent from infiltration of other inflammatory cells including monocytes and macrophages, has been reported in nanoparticle-induced lung inflammation [10]. However, the level of inflammatory cytokines including TNF- $\alpha$ and IL- 6 was significantly reduced by THP in nanoparticle-induced lung inflammation. These results are in line with our findings, even without reaching statistical significance due to high individual variations within all groups at these early time points after SBTx. The evaluation of systemic reactions regarding IL- 6 serum levels stands in line with the decrease of IL- 6 mRNA expression in the early phase after transplantation in the present study.

In response to surgical manipulation and I/R injury, a relevant neutrophil infiltration occurs early after SBTx in the smooth muscle layer $[15,22]$. The inflammatory response is intensified during reperfusion contributing to smooth muscle dysfunction [22]. In the present study, neutrophil infiltration in the smooth muscle layer showed a 68-fold increase in isogenic controls compared to nontransplanted controls at $24 \mathrm{~h}$ after transplantation. At this time point, THP treatment prevented neutrophil infiltration by almost $60 \%$. This reduction of neutrophil infiltration by THP is most probably related to the decreased formation of proinflammatory cytokines in THP-treated animals, especially in the early phase $(3 \mathrm{~h})$ after transplantation. Again, the reduction of cytokine transcription by THP was not statistically significant, which might be in part due to the unchanged infiltration of monocytes and macrophages even in THP-treated animals. Previous findings [15] indicate that the infiltration of ED1-positive cells correlates well with the extent of inflammatory reactions in the graft muscularis triggered by further cytokine production upon activation of these cells. This could also explain the rather mild protective effects of THP on smooth muscle function, which has been shown to be related to the excretion of NO by iNOS induction in the setting of intestinal transplantation [23]. Nevertheless, NO serum levels were decreased by THP treatment at both time points displaying the protective capacity regarding systemic reactions liberated by I/R injury. However, statistical significance was not reached, which may be also due to high standard deviations in vehicle-treated groups. 
Although several reports suggest a protective effect of THP not only in cells [24-26] but also as a potential therapeutic agent in several diseases [13, 27-29], its mechanism of action in mammalian cells is widely unclear. Nevertheless, THP is still believed to be compatible with cellular metabolism and function as initially described [3]. Up to now, no toxic potential in mammalian cells was identified [10]. Due to its hydrophilic nature, the protective impact of THP is believed to be liberated by mainly extracellularly exerted cell membrane protection. It has been shown that THP increases the hydration of the surface of a model membrane raising the mobility of polar lipid head groups and hence membrane fluidity [30]. Since signaling cascades are initiated particularly at cellular plasma membranes, the ability of THP to modulate membrane fluidity could explain both its tissue-protective and its anti-inflammatory potential.
Based on our findings, we suggest that THP might be a useful supplement in a combined therapeutic approach to overcome I/R injury. In our hands, its protective potential improves primarily the tissue quality of the mucosa layer as predicted by Wei et al. [2]. Regarding the muscle layer, the main benefit of THP is the considerable reduction of neutrophil infiltration based most probably on the amelioration of initial inflammatory processes.

\section{Acknowledgements}

This study was supported by a grant from the Deutsche Forschungsgemeinschaft (KFO 115/1-1, Teilprojekt 3) and by the Bonfor-Program of the University of Bonn (O-112.0024, O-112.0013 and O-112.0015).

\section{References}

1 Land WG: The role of postischemic reperfusion injury and other nonantigen-dependent inflammatory pathways in transplantation. Transplantation 2005;79:505-514.

-2 Wei L, Wedeking A, Buttner R, Kalff JC, Tolba RH, van Echten-Deckert G: A natural tetrahydropyrimidine protects small bowel from cold ischemia and subsequent warm in vitro reperfusion injury. Pathobiology 2009; 76:212-220.

-3 Galinski EA, Pfeiffer HP, Truper HG: 1,4,5,6-Tetrahydro-2-methyl-4-pyrimidinecarboxylic acid. A novel cyclic amino acid from halophilic phototrophic bacteria of the genus Ectothiorhodospira. Eur J Biochem 1985;149:135-139.

4 Rengpipat S, Lowe SE, Zeikus JG: Effect of extreme salt concentrations on the physiology and biochemistry of Halobacteroides acetoethylicus. J Bacteriol 1988;170:3065-3071.

5 Arora A, Ha C, Park CB: Inhibition of insulin amyloid formation by small stress molecules. FEBS Lett 2004;564:121-125.

-6 Schnoor M, Voss P, Cullen P, Boking T, Galla HJ, Galinski EA, Lorkowski S: Characterization of the synthetic compatible solute homoectoine as a potent PCR enhancer. Biochem Biophys Res Commun 2004;322:867-872.

7 Andersson MM, Breccia JD, Hatti-Kaul R: Stabilizing effect of chemical additives against oxidation of lactate dehydrogenase. Biotechnol Appl Biochem 2000;32:145-153.

8 Buenger J, Driller H: Ectoin: an effective natural substance to prevent UVA-induced premature photoaging. Skin Pharmacol Physiol 2004;17:232-237.
9 Buenger J, Degwert J, Driller H: The protective function of compatible solute ectoin on the skin, skin cells and its biomolecules with respect to UV-radiation, immunosupression and membrane damage. IFSCC Magazine 2001.

10 Sydlik U, Gallitz I, Albrecht C, Abel J, Krutmann J, Unfried K: The compatible solute ectoine protects against nanoparticle-induced neutrophilic lung inflammation. Am J Respir Crit Care Med 2009;180:29-35.

11 Park PO, Haglund U, Bulkley GB, Falt K: The sequence of development of intestinal tissue injury after strangulation ischemia and reperfusion. Surgery 1990;107:574-580.

12 Park PO, Wallander J, Tufveson G, Haglund $\mathrm{U}$ : Cold ischemic and reperfusion injury in a model of small bowel transplantation in the rat. Eur Surg Res 1991;23:1-8.

-13 Kanapathipillai M, Lentzen G, Sierks M, Park CB: Ectoine and hydroxyectoine inhibit aggregation and neurotoxicity of Alzheimer's beta-amyloid. FEBS Lett 2005;579: 4775-4780.

14 Kolp S, Pietsch M, Galinski EA, Gutschow $\mathrm{M}$ : Compatible solutes as protectants for $\mathrm{zy}-$ mogens against proteolysis. Biochim Biophys Acta 2006;1764:1234-1242.

15 Schaefer N, Tahara K, Schuchtrup S, Websky MV, Overhaus M, Schmidt J, Wirz S, AbuElmagd KM, Kalff JC, Hirner A, Turler A: Perioperative glycine treatment attenuates ischemia/reperfusion injury and ameliorates smooth muscle dysfunction in intestinal transplantation. Transplantation 2008; 85: 1300-1310.
16 Schaefer N, Tahara K, von Websky M, Weh ner S, Pech T, Tolba R, Abu-Elmagd K, Kalff JC, Hirner A, Turler A: Role of resident macrophages in the immunologic response and smooth muscle dysfunction during acute allograft rejection after intestinal transplantation. Transpl Int 2008;21:778-791.

17 Schmittgen TD, Zakrajsek BA, Mills AG, Gorn V, Singer MJ, Reed MW: Quantitative reverse transcription-polymerase chain reaction to study mRNA decay: comparison of endpoint and real-time methods. Anal Biochem 2000;285:194-204.

18 Kalff JC, Schraut WH, Simmons RL, Bauer AJ: Surgical manipulation of the gut elicits an intestinal muscularis inflammatory response resulting in postsurgical ileus. Ann Surg 1998;228:652-663.

19 Schaefer N, Tahara K, Schmidt J, Wehner S, Kalff JC, Abu-Elmagd K, Hirner A, Turler A: Resident macrophages are involved in intestinal transplantation-associated inflammation and motoric dysfunction of the graft muscularis. Am J Transplant 2007;7:1062-1070.

20 Schaefer N, Tahara K, Websky MV, Koscielny A, Pantelis D, Kalff JC, Abu-Elmagd K, Hirner A, Turler A: Acute rejection and the muscularis propria after intestinal transplantation: the alloresponse, inflammation, and smooth muscle function. Transplantation 2008;85: 1465-1475.

21 Takeyoshi I, Zhang S, Nomoto M, Zhu Y, Kokudo Y, Suzuki T, Hamada N, Nemoto A, Starzl TE, Todo S: Mucosal damage and recovery of the intestine after prolonged preservation and transplantation in dogs. Transplantation 2001;71:1-7. 
-22 Schaefer N, Tahara K, Schmidt J, Zobel S, Kalff JC, Hirner A, Turler A: Mechanism and impact of organ harvesting and ischemia-reperfusion injury within the graft muscularis in rat small bowel transplantation. Transplant Proc 2006;38:1821-1822.

-23 Schaefer N, Tahara K, Pech T, Websky MV, Fujishiro J, Pantelis D, Abu-Elmagd K, Kalff JC, Hirner A, Turler A: Inducible nitric oxide synthase expression in the intestinal muscularis mediates severe smooth muscle dysfunction during acute rejection in allogenic rodent small bowel transplantation. J Surg Res 2008;150:159-168.
24 Graf R, Anzali S, Buenger J, Pfluecker F, Driller H: The multifunctional role of ectoine as a natural cell protectant. Clin Dermatol 2008;26:326-333.

25 Zhang L, Wang Y, Zhang C, Wang Y, Zhu D, Wang C, Nagata S: Supplementation effect of ectoine on thermostability of phytase. Biosci Bioeng 2006;102:560-563.

26 Nagata S, Maekawa Y, Ikeuchi T, Wang YB, Ishida A: Effect of compatible solutes on the respiratory activity and growth of Escherichia coli $\mathrm{K}-12$ under $\mathrm{NaCl}$ stress. J Biosci Bioeng 2002;94:384-389.

27 Pastor JM, Salvador M, Argandona M, Bernal V, Reina-Bueno M, Csonka LN, Iborra JL, Vargas C, Nieto JJ, Canovas M: Ectoines in cell stress protection: uses and biotechnological production. Biotechnol Adv 2010;28: 782-801.
28 Furusho K, Yoshizawa T, Shoji S: Ectoine alters subcellular localization of inclusions and reduces apoptotic cell death induced by the truncated Machado-Joseph disease gene product with an expanded polyglutamine stretch. Neurobiol Dis 2005;20:170-178.

29 Kanapathipillai M, Ku SH, Girigoswami K, Park CB: Small stress molecules inhibit aggregation and neurotoxicity of prion peptide 106-126. Biochem Biophys Res Commun 2008;365:808-813.

30 Harishchandra RK, Wulff S, Lentzen G, Neuhaus T, Galla HJ: The effect of compatible solute ectoines on the structural organization of lipid monolayer and bilayer membranes. Biophys Chem 2010;150:37-46. 